\title{
UCRL-TR-233957
}

LAW RENCE LIVERMORE N A T IO N A L LABORATORY
Exploring Viral Genomics at Lawrence Livermore National Laboratory

K. Kilpatrick, A. Hiddessen

August 24, 2007 
This document was prepared as an account of work sponsored by an agency of the United States Government. Neither the United States Government nor the University of California nor any of their employees, makes any warranty, express or implied, or assumes any legal liability or responsibility for the accuracy, completeness, or usefulness of any information, apparatus, product, or process disclosed, or represents that its use would not infringe privately owned rights. Reference herein to any specific commercial product, process, or service by trade name, trademark, manufacturer, or otherwise, does not necessarily constitute or imply its endorsement, recommendation, or favoring by the United States Government or the University of California. The views and opinions of authors expressed herein do not necessarily state or reflect those of the United States Government or the University of California, and shall not be used for advertising or product endorsement purposes.

This work was performed under the auspices of the U.S. Department of Energy by University of California, Lawrence Livermore National Laboratory under Contract W-7405-Eng-48. 


\section{Exploring Viral Genomics at Lawrence Livermore National Laboratory}

\section{Internship Project}

\section{An Overview of $\mathrm{VICl}$}

This summer I had the privilege of working at Lawrence Livermore National Laboratory under the Nonproliferation, Homeland and International Security Directorate in the Chemical and Biological Countermeasures Division. I worked exclusively on the Viral Identification and Characterization Initiative ( $\mathrm{VICl}$ ) project focusing on the development of multiplexed polymerase chain reaction (PCR) assays. The goal of $\mathrm{VICl}$ is to combine several disciplines such as molecular biology, microfluidics, and bioinformatics in order to detect viruses and identify them in order to effectively and quickly counter infectious disease, natural or engineered. The difficulty in such a countermeasure is that little is known about viral diversity due to the ever changing nature of these organisms. In response, $\mathrm{VICl}$ is developing a new microfluidicbioanalytical platform to detect known and unknown viruses by analyzing every virus in a sample by isolating them into picoliter sized droplets on a microchip and individually analyzing them. The sample will be injected into a channel of oil to form droplets that will contain viral nucleic acids that will be amplified using PCR. The multiplexed PCR assay will produce a series of amplicons for a particular virus genome that provides an identifying signature. A device will then detect whether or not DNA is present in the droplet and will sort the empty droplets from the rest. From this point, the amplified DNA is released from the droplets and analyzed using capillary gel electrophoresis in order to 
read out the series of amplicons and thereby determine the identity of each virus. The following figure depicts the microfluidic process.

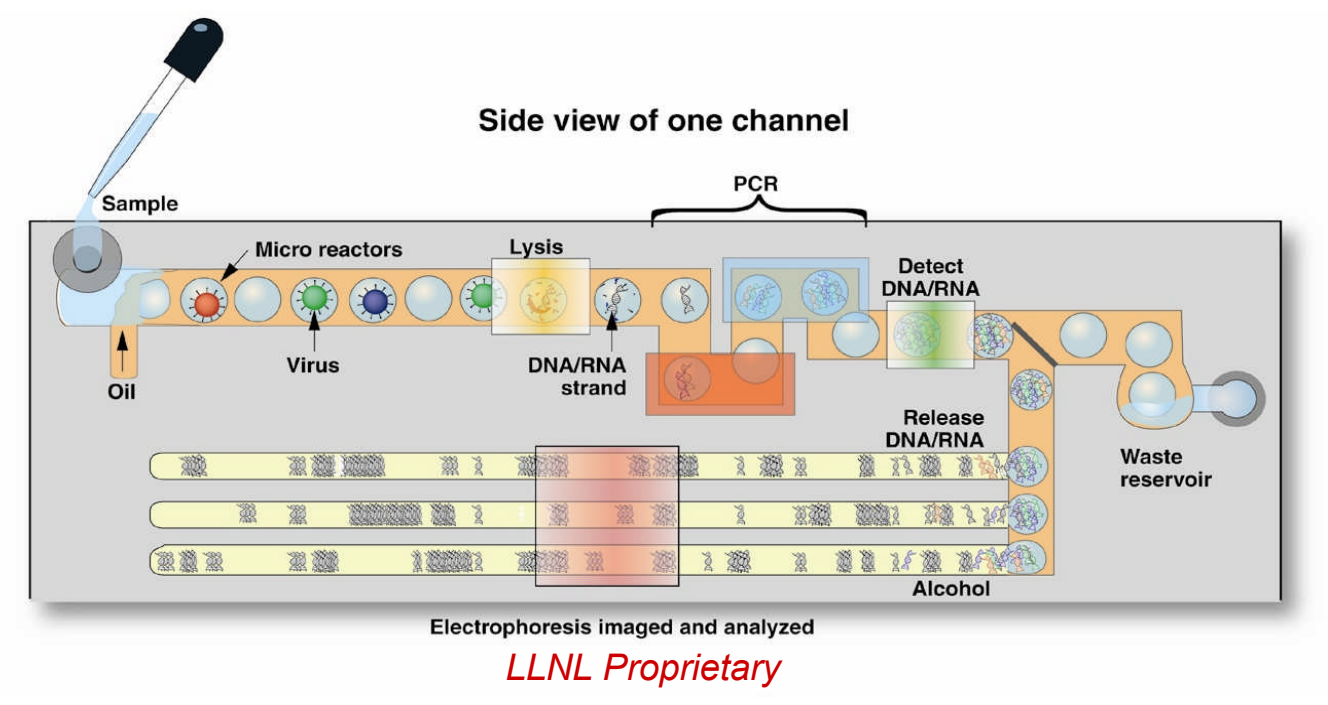

Figure 1: Overview of how the platform will sort, amplify, and analyze the microdroplets in order to characterize and identify viruses.

For the abovementioned microfluidic process to work, a method for detecting amplification of target viral nucleic acids that does not interfere with the multiplexed biochemical reaction is required for downstream sorting and analysis. In this report, the successful development of a multiplexed PCR assay using SYBR Green I as a fluorescent dye to detect amplification of viral DNA that can later be integrated into microfluidic PCR system for sorting and analysis is shown.

\section{Assay Development for VICI}

My specific role in the $\mathrm{VICl}$ project was to develop an assay for multiplex PCR assay using SYBR Green I as a fluorescent dye to detect amplification of viral DNA that can later be integrated into microdroplet PCR for both droplet sorting and viral identification. As PCR products are generated in the microdroplets, real time detection 
with an intercalating nucleic acid dye will signal that the isolated virus has been amplified. This initially was tested using single-plex PCR with purified viral DNA. The concentration of SYBR Green I was varied in order to optimize the detection of amplified DNA. Next, the affects of SYBR Green I was tested with a multiplex PCR. Each PCR was analyzed using $3 \%$ agarose gel electrophoresis in order to figure out the amplicon size. The results showed that amplification using SYBR Green I for detection can be achieved for single and multiplex PCR. For the single-plex PCR, concentrations of SYBR Green I that were higher than 1X contained no visible band at 383-bp as shown below.

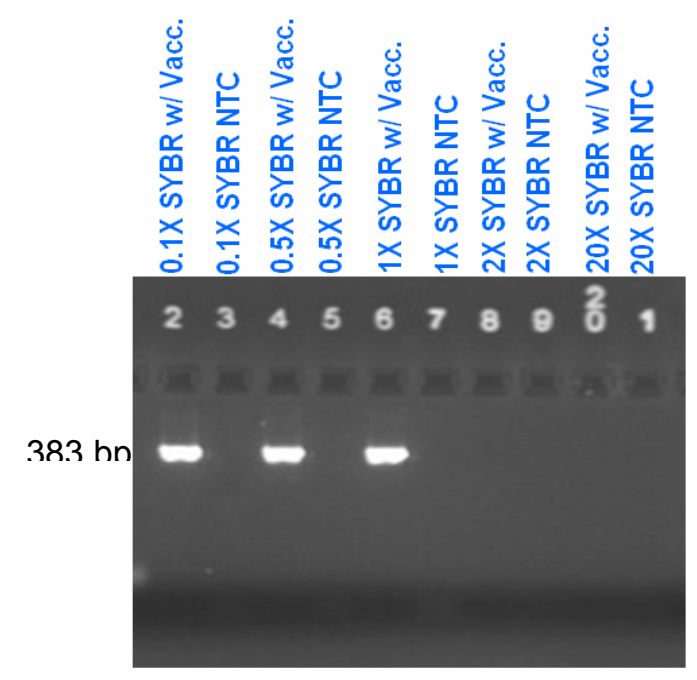

Figure 2: 3\% agarose gel electrophoresis analyses of single-plex PCR with viral DNA in the presence of SYBR Green I.

For the multiplexed PCR, concentrations of SYBR Green I higher that 2X did not show all 5 bands in a " 5 -plex". It was evident that as the concentration of SYBR Green I increases, the strength of the bands decreases. More so, the bands were stronger when 
the concentration of the primers is weighted based on amplicon size. Figure 3 depicts the results of varying the concentration of SYBR Green I in a 5-plex.

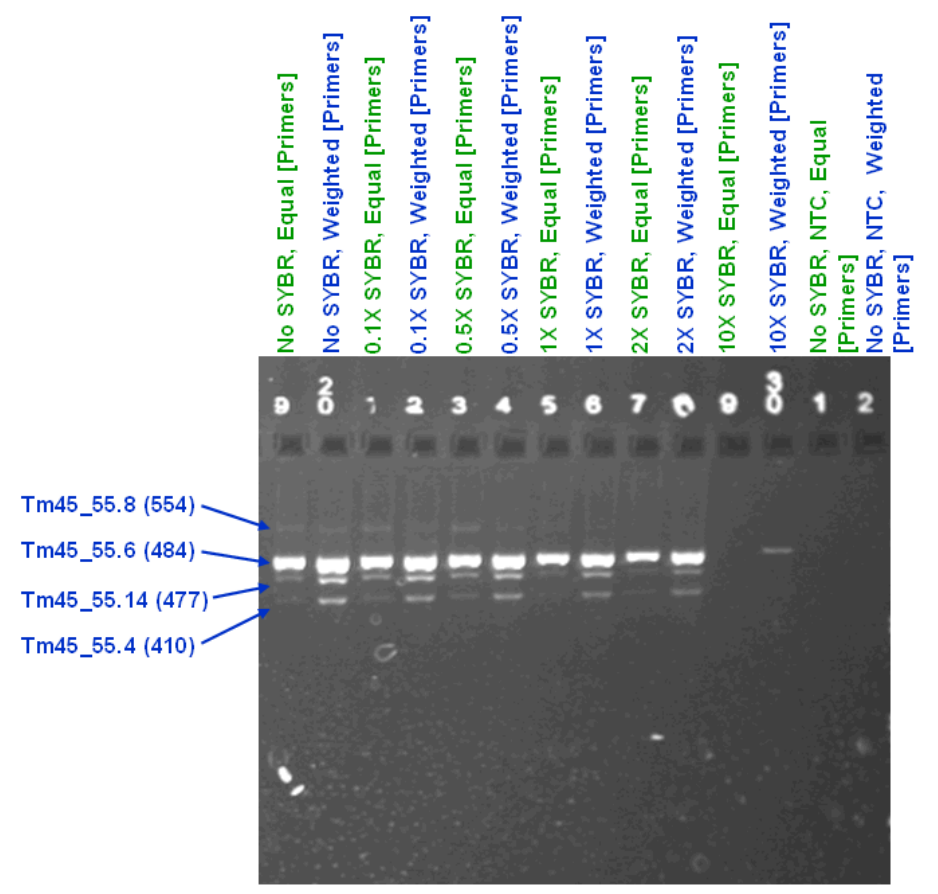

Figure 3: 3\% agarose gel electrophoresis analyses of multiplexed PCR with viral DNA in the presence of SYBR Green I.

At high concentrations of SYBR Green I, the PCR reaction is inhibited and no product can be visualized using gel electrophoresis. The optimal concentration of SYBR Green I for a single-plex PCR reaction is $1 \mathrm{X}$ and $0.5 \mathrm{X}$ for a 5-plex PCR reaction. The next steps were be to use FAM labeled primers for identifying and characterizing viral DNA, and perform capillary gel electrophoresis for analysis of the product. Capillary gel electrophoresis is more accurate and less time intensive than agarose slab gel electrophoresis. Thus, capillary gel electrophoresis is a promising analytical method for rapid identification of potential threats via the read-out of viral signatures. I have aided in the development of a protocol for capillary electrophoresis by preparing the samples to be analyzed on the machine and then comparing it to the traditional gel electrophoresis 
and know amplicon size. The machine runs the samples through a charged matrix that separates the DNA fragments according to size with the smallest running through the capillaries the fastest and then compares the size of the fragment to a standard. A sample graph from a capillary electrophoresis machine is depicted in Figure 4.

a.

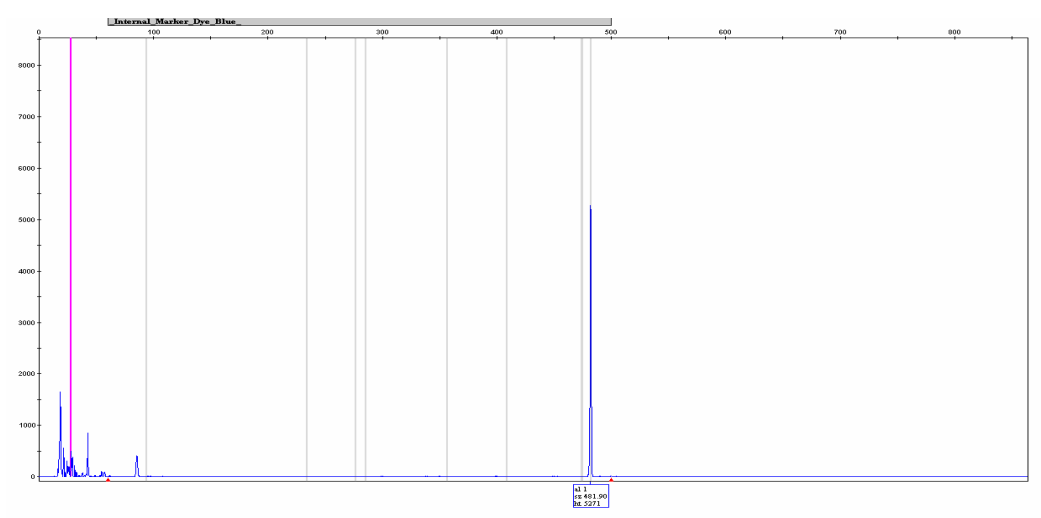

b.

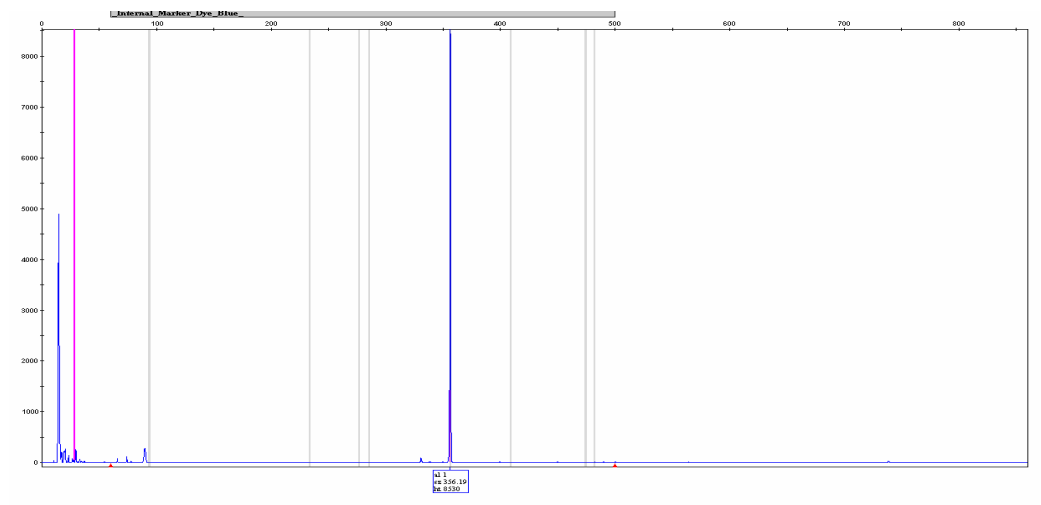

Figure 4: Fragment size determined by capillary electrophoresis. Figure 4a shows an amplicon size of 482 and Figure $4 \mathrm{~b}$ shows an amplicon size of 356.

FAM-labeled primers are simple to work with on a capillary electrophoresis machine using a denaturing gel because the amplified viral DNA is tagged with a fluorescent dye. SYBR Green I, however, only binds to double stranded DNA and when injected to the denaturing gel in the capillaries, the DNA peels apart and the intercalating dye falls off the DNA making it undetectable to the machine. By using the 
FAM-labeled primers with SYBR Green I, amplification of the viral DNA can be detected on the chip via SYBR Green I and the size can be determined via FAM fluorescence. This is a significant milestone reached in the project because it provides options for sorting the drops on the microchip while still being able to effectively archive each DNA signature.

Also as member of the team, I contributed data for posters made to explain the $\mathrm{VICl}$ project in a review from the Department of Homeland Security as well as I made my own poster specializing in my internship project for the lab's Summer Student Poster Symposium. It is possible that the data I have generated this summer will be used in publications.

\section{Impact on Academic and Career Planning}

The time spent at Lawrence Livermore National Laboratory has given me the ability to conduct solid research without the distractions of school. This has enabled me to make an unbiased decision on whether or not I would like to continue research in the future. The experience has also shed light on what it is like to work for the government and dealing with a bureaucracy. Research at a university is much different than at a national lab. At a national laboratory, strict rules and procedures are put in place to ensure the safety of the employees and community as well as the institute itself. In a university setting, the atmosphere is much more relaxed. I have thoroughly enjoyed the project and team that I have worked with and it has helped me decide on my future education and career goals. Prior to my internship appointment, I had already decided that I would continue onto graduate school, but was unsure if I wanted to pursue a 
masters or doctoral program. After much consideration, I feel as though an industry type setting would be more appealing for career goals in working with pharmaceuticals and pharmaceutical process design. From this I have discovered a masters program at Michigan State University that focuses on pharmaceutical engineering for industry geared professionals. See as though I graduate in December of 2007, I am highly considering returning to Lawrence Livermore National Laboratory to work on the $\mathrm{VICl}$ project in the off time between undergraduate school and graduate school. This would allow me to continue on the project I started this summer and expand into other projects in the laboratory if desired.

In my time at Lawrence Livermore National Laboratory, I had the privilege in attending several seminars and tours. Weekly, the Department of Homeland Security Scholars and Fellows would meet during lunch for a "brown bag" lunch and listen to lab employees discuss various projects that promote homeland security. Some of these topics included the $\mathrm{VICl}$ project, nuclear detection for protection of our borders, and how countermeasure research and development can be translated into effective national security applications. I especially enjoyed the discussion about nuclear detection because the presenter clearly explained the strategies to detect the acquisition, transport, and use the radiological and nuclear material against the United States. More so, he engaged the audience with several operational scenarios which shed light to how the technologies we develop are used in the field. Also in my time at Lawrence Livermore National Laboratory, I attended several seminars given by other departments which included talks about the National Ignition Facility (NIF), a conference with Secretary Linda Adams, Cal EPA, discussing global climate change and how California 
is being proactive, and various others. It was amazing to what else was going on around the laboratory.

Several tours were also available to the summer students. I attended a tour of NIF and was able to see the target chamber and the "three football field" sized building of lasers that make up the largest and most complex laser/optical system in the world. I also had the privilege to attend a tour of the Joint Genome Institute (JGI) in Walnut Creek while working at the lab. The tour included a detailed description of the facility's contribution to sequencing the human genome and how the sequencing process works. I was able to see the sequencing process in action which used robotic instrumentation which takes the process to an industrial scale. It was interesting to see that the JGI has taken a new direction in genomic sequencing and focusing on the development of biofuels since the facility is a part of the Department of Energy. And lastly, I toured Lawrence Livermore National Laboratory's Site 300 where explosives are made, fired and tested. The imaging capabilities at Site 300 when firing explosive is state of the art and shows detailed film of the explosion and impact to the materials they are testing against the explosive such as armor. Lawrence Livermore National Laboratory has a variety of different research opportunities and it was educational to see how a chemical engineer, like me, can contribute to several diverse projects.

\section{Suggested Areas of Research}

The Department of Homeland Security is always looking for new areas to look into in order to further their missions and the options are limitless. Working to develop vaccines or a protocol to quickly develop vaccines in response to identifying and 
characterizing emerging or engineered viruses would prove to be essential in shortening response time. Detection is an important step but the reaction can be as equally time consuming. Furthermore, educating the public is always important. The government's communication with the public should be strengthened as well as the public's communication with its government. With a more educated public, detection and response to potential terrorism attacks can be become a community's responsibly not just that of a few.

Overall, this summer at Lawrence Livermore National Laboratory has taught me more than just academic knowledge but lasting work ethics and how to network. In my time here, I have made countless contacts that will prove to be valuable in the future. I look forward to returning in the future. 